
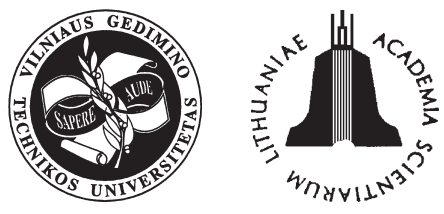

ISSN 1648-4142 TRANSPORT

www.transport.vtu.lt

TRANSPORT - 2005, Vol XX, No 4, 135-140

\title{
DETERMINATION OF CAR RUN UP - BRAKING AND MANOEUVRING PARAMETERS IN AN EMERGENCY SITUATION IN THE CASE OF LIMITED ROAD SEGMENT
}

\author{
Ona Lukoševičiené ${ }^{1}$, Robertas Pečeliūnas ${ }^{2}$ \\ Dept of Automobile Transport, Vilnius Gediminas Technical University, \\ J. Basanavičiaus g. 28, LT-03224 Vilnius, Lithuania \\ E-mail: 1tiauto@ti.vtu.lt, ${ }^{2}$ robertas.peceliunas@ti.vtu.lt \\ Received 2005-01-07; accepted 2005-05-25
}

\begin{abstract}
As the traffic intensity on roads increases, the number of road accidents also increases and the situations become more and more complicated. The presented method of reconstruction of preaccidental situations with the purpose of examination of road accident mechanisms can be widely used for the investigation of road accidents of different nature and for the determination of their reasons, the distance run by a car, the time of its run and speed which can be reached during the run up and followed by braking in road segments between two manoeuvres in a road segment of limited length. This method is being widely used in Lithuania for the investigation of accidental situations and for the assurance of law and order.
\end{abstract}

Keywords: run up, braking, manoeuvre, time, distance, road accident.

\section{Introduction}

As Lithuanian road transport flows into the EU transport flow, adjustment of Lithuanian transportation (orders, routes), traffic intensity, road building and maintenance, work of car service stations, supply of spare parts and achievement of safety level on the roads to those existing in the EU are of great importance. The world experience shows that some negative results of automobilization spread - road accidents - now are unavoidable, but their control, appropriate and skilled fixation, analysis and pertinent legal evaluation are also very important. In other words, a scientifically based method is necessary for the examination and investigation of road accidents. It must be created.

Now in our country our technical experts use the methods established as far back as Soviet time and the methods and software brought (sometimes illegally) from the Western countries [1-3]. This is obviously necessary and unavoidable, however, insufficient. The main thing is that such methods would be scientifically well-founded and could help to restore objectively any road accident up to its initial stage - as far back as the conflict had arisen. Later it develops into a dangerous stage and finally - into an emergent one (when the road accident becomes unavoidable). The Department of Automobile
Transport of the Vilnius Gediminas Technical University is engaged in the creation of such methods which help to "untangle" highly complicated situations and circumstances which sometimes cannot be described and recorded in a qualified and precise manner (sometimes they are destroyed by washing off with fire fighting vehicles) by investigation staff arriving to the accident spot. They can often be forgotten by the victims or other witnesses because of shock situation or "kept back" by car drivers [47]. But for many situations there are no methods yet and road accidents become more and more intricated, their amount increases.

Among some frequent controversial road situations precedent to a road accident is one, for instance, when a driver, making the right turn into the main road with more than one traffic lane hurrying crosses the lanes up to the road axial line simultaneously braking the car to the speed safe for side slide intending later to turn left (e.g., into a court) or even to turn round. At the same time some another driver drives his car on the left lane of the main road adjacent to the road axis and has no time to reduce his speed and a crash happens. A conflict arises. The question is - which driver has infringed traffic regulations and provoked the dangerous situation in the following road accident? Technical experts cannot rely on testifying of drivers and witnesses and cannot 
take them into account. The real situation is to be restored based on the objective facts only using the knowledge of vehicle dynamics, strength of materials, theoretical mechanics, physics and s.o., and by the calculations, if necessary, deducing even missing formulas for the restoration of specific situations $[8$, 9].

We shall analyse the aforementioned situation trying to apply the known physical laws to the concrete situation, deducing formulas for the determination of vehicle motion parameters (speed, time) in the preaccidental situation (see Fig).

\section{Analysis}

Suppose a car makes the right turn into the main road with a maximum possible speed $v_{1}$, safe from side slide. Till the next turn, for instance, to left, the distance $S$ in the longitudinal direction of the road is to be run at first with the acceleration up to such maximum speed $v_{2}$, that after transit into the 2-nd traffic lane for the left turn it would be possible to reduce the car speed to the maximum possible speed $v_{3}$, safe from side slide $[10,11]$. So all the route is formed of 2 stages: run up and slowing down.

The kinematic equation of a steady motion during run up is:

$$
S^{I}=v_{1} t^{I}+\frac{a\left(t^{I}\right)^{2}}{2},
$$

here $a$-acceleration after the right turn into the main road (e.g. 2 traffic lanes in one direction); $t^{I}$ - time of car run up to speed $v_{2}=v_{\max } ; S^{I}$ - distance run on the main road during the run up.

On the other hand, acceleration in the road segment $S^{I}$ is:

$$
a=\frac{v_{2}-v_{1}}{t^{I}} \quad \text { or } \quad t^{I}=\frac{v_{2}-v_{1}}{a},
$$

here $v_{1}$ and $v_{2}$-car speed in the beginning and at the end of the run up.

Substitution of time value from equation (2) to equation (1) results in the distance run during the run up:

$$
S^{I}=v_{1} \frac{v_{2}-v_{1}}{a}+\frac{a}{2} \cdot \frac{\left(v_{2}-v_{1}\right)^{2}}{a^{2}}=\frac{v_{2}^{2}-v_{1}^{2}}{2 a} .
$$

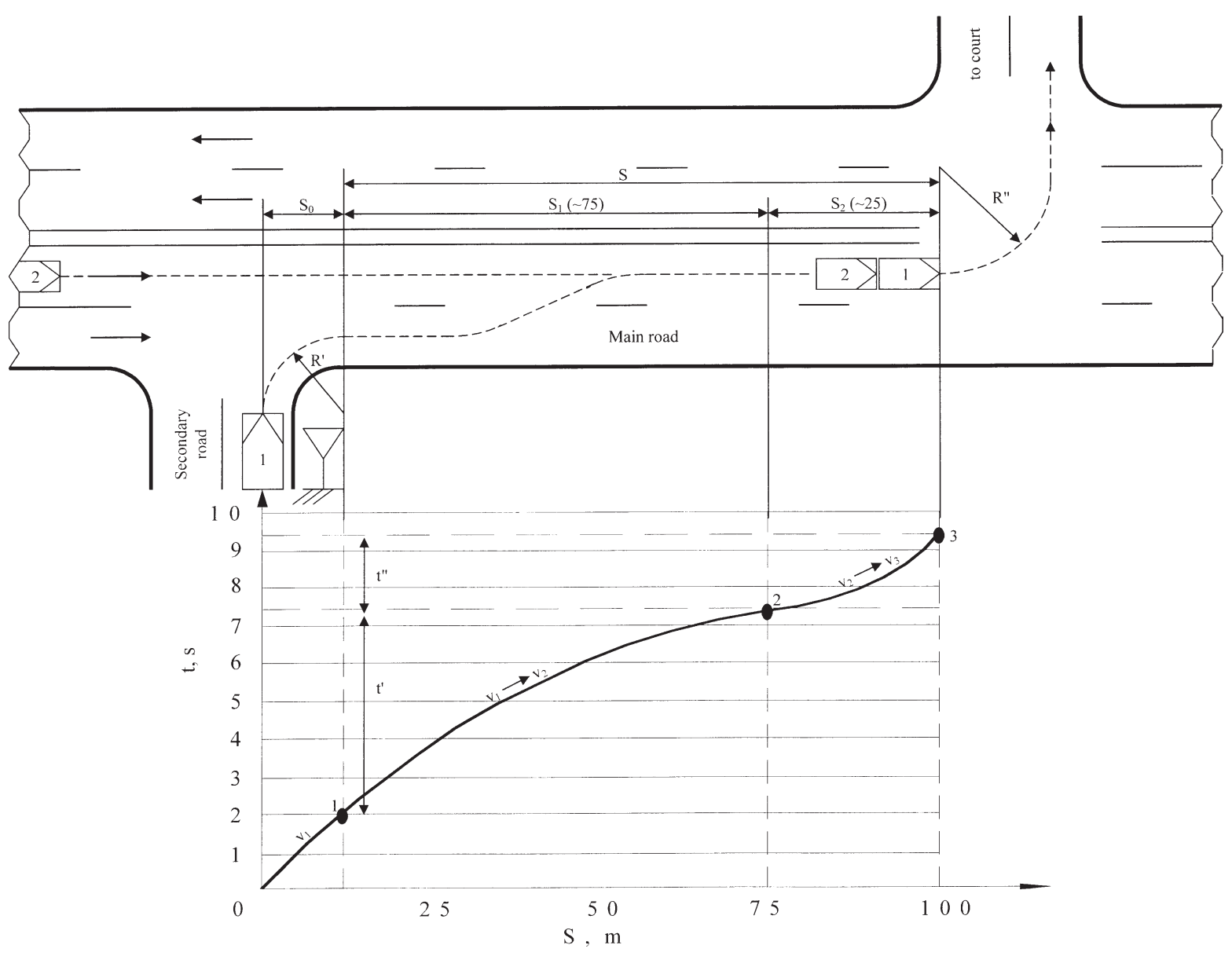

Situational plan of the road accident spot 
On the other hand distance $S^{I I}$ run by the car during time interval in which the car speed altered from $v_{2}$ to $v_{3}$, will be:

$$
S^{I I}=v_{2} t^{I I}+\frac{j\left(t^{I I}\right)^{2}}{2},
$$

here $j$ - deceleration during braking or slowing down (e.g. by engine); $t^{I I}$ - time of braking or slowing down to speed equal to $v_{3}$;

$$
j=\frac{v_{2}-v_{3}}{t^{I I}} \quad \text { or } \quad t^{I I}=\frac{v_{2}-v_{3}}{j} .
$$

Distance $S^{I I}$ run during braking (or slowing down) from speed $v_{2}$ to speed $v_{3}$, is found by the substitution of time value from the (5)-th equation into the (4)-th equation:

$$
S^{I I}=v_{2} \frac{v_{2}-v_{3}}{j}-\frac{j}{2} \cdot \frac{\left(v_{2}-v_{3}\right)^{2}}{j^{2}}=\frac{v_{2}^{2}-v_{3}^{2}}{2 j} .
$$

Knowing that run up distance $S^{I}$ and slowing down distance $S^{I I}$ constitute in total distance $S$, after the addition of equations (3) and (6) we get:

$$
S=\frac{v_{2}^{2}-v_{1}^{2}}{2 a}+\frac{v_{2}^{2}-v_{3}^{2}}{2 j}
$$

and the total time for acceleration and deceleration is:

$$
T=t^{I}+t^{I I}=\frac{v_{2}-v_{1}}{a}+\frac{v_{2}-v_{3}}{j} .
$$

So the maximum speed which can be reached and followed by slowing down to the safe left turn can be found according to the formula:

$$
v_{2}=v_{\max }=\sqrt{\frac{2 S a j+v_{1}^{2} j+v_{3}^{2} a}{j+a}} .
$$

If the car after run into the main road makes a full stop $\left(v_{1}=0\right)$ and then after run up to the permissible $v_{2}=v_{\max }$ again stops at the road axial line $\left(v_{3}=0\right)$ after reforming for the left turn, the calculations will become simpler and formulas (3), (6), (7), (8) and (9) will seem as follows:

$$
\begin{aligned}
& S^{I}=\frac{v_{2}{ }^{2}}{2 a} ; \\
& S^{I I}=\frac{v_{2}^{2}}{2 j} ; \\
& S=\frac{v_{2}{ }^{2}}{2 a}+\frac{v_{2}^{2}}{2 j}=v_{2}{ }^{2} \cdot \frac{(a+j)}{2 a j} ;
\end{aligned}
$$

$$
\begin{aligned}
& T=\frac{v_{2}}{a}+\frac{v_{2}}{j}=v_{2} \cdot \frac{(a+j)}{a j} ; \\
& v_{2}=v_{\max }=\sqrt{\frac{2 S a j}{a+j}} .
\end{aligned}
$$

If, for instance, the car after turning into the main road can not run up to the maximum possible (it will later have time for slowing down) speed $v_{2}$, but it will run up not exceeding the established restricted speed (e.g., up to $40 \mathrm{~km} / \mathrm{h}$ and s.o.), - it will run some distance at constant speed $v_{2}=$ const in this road interval of length $S$, and nearing after reforming to the left turn point it will slow down to the safe speed $v_{3}$. In such case the distance of car run at constant speed $\left(v_{2}=\right.$ const $)$ will be:

$$
S_{v=\text { const }}=S-\frac{v_{2}^{2}-v_{1}^{2}}{2 a}-\frac{v_{2}^{2}-v_{3}^{2}}{2 j} .
$$

The time of car run at constant speed will be:

$$
T_{v=\text { const }}=\frac{1}{v^{2}}\left(S-\frac{v_{2}^{2}-v_{1}^{2}}{2 a}-\frac{v_{2}^{2}-v_{3}^{2}}{2 j}\right) \text {. }
$$

The total time for this "route" there will be:

$$
T=\frac{v_{2}-v_{1}}{a}+\frac{v_{2}-v_{3}}{j}+\frac{1}{v_{2}}\left(S-\frac{v_{2}^{2}-v_{1}^{2}}{2 a}-\frac{v_{2}^{2}-v_{3}^{2}}{2 j}\right)
$$

or

$$
T=\frac{1}{v_{2}}\left(S+\frac{\left(v_{2}-v_{1}\right)^{2}}{2 a}+\frac{\left(v_{2}-v_{3}\right)^{2}}{2 j}\right) .
$$

Below we shall illustrate the practical application of these formulas, how they were used in the examination of traffic accidents occurred in reality.

Example 1. Driver $A$ of the 1-st car after the right turn from a court into the main road with two traffic lanes in one direction after 100 meters and after reforming into the 2-nd traffic lane has to make a left turn into a court located on the other side of the street; but after the reforming beside the road axial line and after slowing down the car before the left turn, the 2-nd car, driven by driver $B$ in the 2-nd traffic lane in the same direction stricks the rear end of the 1-st car.

Driver A asserted that before his drive into the main road the 2-nd car was rather far and did not cause any danger for the reforming and for the left turn; but driver $B$ asserted that when he was driving in the 2-nd traffic lane he was overtaken on the right side by driver $A$ who suddenly made the left turn and blocked the lane by his (the 1-st) car and provoked the collision.

The investigator was asked among other questions also to answer the question, if driver's B statement is right or wrong. 
During the technical examination the investigator at first established that maximum speed of the 1-st car after its right turn into the main road because of side slim safety could not exceed $v_{1}=18 \mathrm{~km} / \mathrm{h}=5 \mathrm{~m} / \mathrm{s}$. Besides it was found by technical calculations that at the moment of collision the speed of the 1-st car was $v_{A}=v_{3}=21.6 \mathrm{~km} / \mathrm{h}=6 \mathrm{~m} / \mathrm{s}$ and the speed of the 2nd car was $v_{B}=54 \mathrm{~km} / \mathrm{h}=15 \mathrm{~m} / \mathrm{s}$.

In accordance with the formula (1) the maximum speed $v_{2}$, was found which could be reached by the 1-st car in the forementioned road segment $S=100 \mathrm{~m}$ after its reforming to the road axial line before the left turn and slowing the speed down to $v_{3}=21,6 \mathrm{~km} / \mathrm{h}=6 \mathrm{~m} / \mathrm{s}$. This speed was $v_{2}=58 \mathrm{~km} / \mathrm{h}=16,1 \mathrm{~m} / \mathrm{s}$ :

$$
\begin{aligned}
& v_{2}=v_{\max }=\sqrt{\frac{2 S a j+v_{1}^{2} j+v_{3}^{2} a}{j+a}}= \\
& \sqrt{\frac{2 \cdot 100 \cdot 1,5 \cdot 5+5^{2} \cdot 5+6^{2} \cdot 1,5}{5+1,5}}=
\end{aligned}
$$

$16,1 \mathrm{~m} / \mathrm{s} \cong 58 \mathrm{~km} / \mathrm{h}$.

Time for run up and slow down of the 1-st car (driver $A$ ) was $9,4 \mathrm{s:}$

$$
T=\frac{v_{2}-v_{1}}{a}+\frac{v_{2}-v_{3}}{j}=\frac{16,1-5}{1,5}+\frac{16,1-6}{5}=9,4 \mathrm{~s} .
$$

During this time the 2-nd car (driver B), running at the speed $v_{B}=54 \mathrm{~km} / \mathrm{h}=15 \mathrm{~m} / \mathrm{s}$ could run the distance equal approximately to $141 \mathrm{~m}$ :

$$
S_{B}=v_{B} T=15 \mathrm{~m} / \mathrm{s} \cdot 9,4 \mathrm{~s}=141 \mathrm{~m} .
$$

So, when the 1-st car was making the right turn into the main road, the 2-nd car was at the distance of $141 \mathrm{~m}$ from the point of collision and the distance between these cars was equal to $41 \mathrm{~m}$, and during the forementioned speed changes before the left turn driver A of the 1-st car had nobody for overtaking. Also it is to be noted that if driver $A$ did not run up at the maximum possible speed in this road interval (under condition that he would later reduce this speed to safe from side slide during the left turn), equal to $58 \mathrm{~km} / \mathrm{h}$, he ran up at less speed (e.g. maximum permissible in urban areas equal to $50 \mathrm{~km} / \mathrm{h})$ and if he then drove a certain distance (which can be found from formula (3)) at constant speed $v_{\text {const }}$ followed by braking in the 2-nd traffic lane, - in every case he (driver A) would drive that $100 \mathrm{~m}$ distance longer (that time can be found from the equation (4)), and at the moment of his driving into the main road with the right turn the 2-nd car would be at a greater distance from the point of collision and the distance between the two cars would be greater.

The performed calculations showed that drivercs
$B$ version was wrong because it was impossible in a technical sense.

Example 2. Driver A of car 1 which was driving in the opposite direction on a traffic lane of $8 \mathrm{~m}$ width road was overtaking the 2-nd car which was driven by driver $B$ and was making a left turn (not in the road crossing) from his (right) traffic lane into a petrol pump territory and collided with the latter one.

At the spot of this road accident on the left road side (seen in the runing direction of the cars) there remained braking tracks of the 1-st car of $S_{\text {st. } 1}=16 \mathrm{~m}$ length, right tracks of which began in the middle of the opposite direction traffic lane, i.e. at about $2 \mathrm{~m}$ distance from the road axis stretched in the straight line declined to left at the angle of $7^{\circ}$ compared with the axis line and ended at the left border of the road at the point of collision, then followed the track of the 1-st car side slide of $S_{\check{S} . S L .1}=17 \mathrm{~m}$ length which finished at the rear wheels of this car stopped after this road accident.

The performed calculations showed that before braking the speed of the 1-st car was about $80 \mathrm{~km} / \mathrm{h}=$ $22,22 \mathrm{~m} / \mathrm{s}$ and speed of the 2-nd car which was making the left turn into the petrol pump territory was not more than approximately 17,5 km/h@4,85 m/s.

Later the examination showed that $A$ driver's reaction when he began to prepare for the left turn and braking began at the distance equal to $S_{a}=52,2 \mathrm{~m}$ from the point of collision:

$$
\begin{aligned}
& S_{a}=\left(t_{1}+t_{2}+t_{v}+0,5 t_{3}\right) v_{1}+R_{\min } \sin \alpha+ \\
& S_{S T .1}=(0,6+0,2+0,2+0,5 \cdot 0,3) 22,22+ \\
& 85 \cdot 0,125+16=52,2 \mathrm{~m},
\end{aligned}
$$

here $t_{1}$-driver's respond time in situation before the accident $(0,6 s) ; t_{2}$ - time of initialization of the braking drive $(0,2 s) ; t_{v}$ - time of initialization of the steering drive $(0,2 \mathrm{~s}) ; t_{3}$ - time of deceleration growth $(0,3 \mathrm{~s})$; $R_{\text {min }}-$ minimum radius of the rear right wheel turn without rise of side slide:

$$
R_{\min }=\frac{v_{1}^{2}}{g \varphi_{\check{s}}}+0,5 B=\frac{22,22^{2}}{9,81 \cdot 0,6}+0,5 B=84,75 \cong 85 \mathrm{~m},
$$

here $\varphi_{\breve{s}}$-coefficient of sliding friction (for side slide) of wheel-road pair for road conditions which existed at the moment of the accident $(0,6) ; B$ - width of the 1-st $\operatorname{car}(1,7 \mathrm{~m})$.

Already in the beginning of driver's $A$ respond to the arised danger for traffic safety he drove in the opposite direction traffic lane at the distance $\Delta=0,53 \mathrm{~m}$ approximately from the axial line of the road which divided traffic flows of reverse directions:

$\Delta=4-2-\Delta_{1}-\Delta_{2}=4-2-0,82-0,64=0,53 m$,

here " 4 " - width of the opposite direction traffic lane; $\Delta_{1}$-distance (interval) of movement of the 1-st car in 
direction transversal to the road during the increase of its deceleration up to the maximum value (i.e. when the visible track of wheel braking began:

$$
\Delta_{1}=S_{3} \cdot \sin \alpha=6,66 \cdot 0,125=0,83 m,
$$

here $S_{3}$-distance run by the 1-st car turned to left, until the growth of deceleration reached the maximum value:

$S_{3}=t_{3} \cdot v_{1}=0,3 \cdot 22,22=6,66 \mathrm{~m}$.

$\Delta_{2}$ - distance (interval) of movement of the 1-st car in the direction transversal to the road during its rotation to left at angle $\alpha=7^{0}$ approximately:

$$
\Delta_{2}=R_{\min }(1-\cos \alpha)=85 \cdot(1-0,9925)=0,64 \mathrm{~m} .
$$

Car 1 which was running in the right (rightly its) traffic lane after car 2 (which was being overtaken), in the beginning of the overtaking, i.e., during reforming into the opposite direction traffic lane in the road interval of distance $\Delta_{3}=B+\Delta \cong 2.2 \mathrm{~m}$ (from the crossing of the road axis line, i.e., from the moment of such „reforming“, when driver B of the 2-nd car could take notice of the overtaking 1-st car, till the end of the „reforming", when the 1-st car (its right side) was at distance of $0.53 \mathrm{~m}$ from the road axis), had to run without a side slide the distance $S_{1 L}=32 \mathrm{~m}$ in the longitudinal direction of the road:

$$
S_{1 L}=\sqrt{\frac{8 v^{2} y}{0,8 g \varphi_{\check{s}}}}=\sqrt{\frac{8 \cdot(22,22)^{2} \cdot 2,2}{0,8 \cdot 9,81 \cdot 0,6}} \cong 43 \mathrm{~m} .
$$

From other (not shown here) calculations it is seen that driver $A$ of the 1-st car began the overtaking (crossed the axial line) when the car was at the distance $S_{1}^{0} \cong 95$ from the point of collision:

$$
S_{1}^{0}=42,96+52,2 \cong 95 m
$$

and this distance was run by it in about $T^{0}=4,2 \mathrm{~s}$ :

$$
\begin{aligned}
& T_{1}^{0}=\frac{S_{1 L}}{v_{1}}+t_{1}+t_{2}+t_{v}+0.5 t_{3}+\frac{R_{\min } \cdot \sin \alpha}{v_{1}}+ \\
& \frac{v_{1}}{j}-\sqrt{\frac{2}{j} \cdot\left(\frac{v_{1}^{2}}{2 j}-S_{S T .1}-0,5 t_{3} v_{1}\right)}=\frac{43}{22,22}+ \\
& 0,6+0,2+0,2+0,5 \cdot 0,3+\frac{85 \cdot 0,125}{22,22}+\frac{22,22}{7,5}- \\
& \sqrt{\frac{2}{7,5} \cdot\left(\frac{22,22^{2}}{2 \cdot 7,5}-16-0,5 \cdot 0,3 \cdot 22,22\right)}=4,2 \mathrm{~s},
\end{aligned}
$$

here $j$ - steady deceleration during the 1-st car braking $\left(7.5 \mathrm{~m} / \mathrm{s}^{2}\right)$.

From the materials of this case it was seen that the 2-nd car driven by driver $B$ from the beginning of the left turn has moved by the trajectory with the radius of curvature $R=4 m$ to the petrol pump territory (from the axial line of the road) until the point of collision and has run the distance $S_{2}=6,3$ at the speed safe from the side slide not exceeding 17,5 km/h = 4,85 m/s: $v_{2}=\sqrt{127 \cdot R \varphi_{\check{s}}}=\sqrt{127 \cdot 4 \cdot 0,6} \cong 17,5 \mathrm{~km} / \mathrm{h}=4,85 \mathrm{~m} / \mathrm{s}$, here $R$ - minimum radius of the left turn trajectory as shown in the map of the accident spot drawn by the Road Police $(R=4 \mathrm{~m})$.

So the 2-nd car was moving along the left turn trajectory during the time interval $T_{2}=1,3 \mathrm{~s}$ :

$$
T_{2}=\frac{S_{2}}{v_{2}}=\frac{6,3}{4,85}=1,299 \cong 1,3 \mathrm{~s} .
$$

As it is seen from the calculations driver $B$ of the 2-nd car began the left turn to the territory at 2,9 s later than driver $A$ of the 1-st car began his overtaking:

$$
\Delta T=T_{1}^{0}-T_{2}=4,2-1,3=2,9 s,
$$

and driver $A$ responded preparing for braking and turn to the left which resulted at the angle of $7^{\circ}$ when he was already completely in the opposite traffic lane and when driver $B$ did not begin yet his movement by the left turn curve (may be, it was driver's A respond to the left turn signal of the 2-nd car):

$$
\begin{aligned}
& T_{1}=t_{1}+t_{2}+t_{v}+0,5 t_{3}+\frac{R_{\min } \cdot \sin \alpha}{v_{1}}+\frac{v_{1}}{j}- \\
& \sqrt{\frac{2}{j}\left(\frac{v_{1}^{2}}{2 j}-S_{S T .1}-0,5 t_{3} \cdot v_{1}\right)} \cong 2,3 \mathrm{~s} .
\end{aligned}
$$

So:

$$
T_{1}=2,3 s>T_{2}=1,3 s \text {. }
$$

\section{Conclusion}

The presented method (see formulas (1), (2) and (3)) for the reconstruction of a preaccidental situation of a road accident can be widely used in the examination of road accidents of different origin and their reasons when the distance run by a car, its run time, speed which could be reached by the car between some two manoeuvres and so. are to be evaluated. Example 2 shows still more wide application of the suggested method, e.g. in the case of an unsuccessful overtaking and so.

Another example. Driver of car A, passing car $B$ which ran from the opposite direction paid attention that a blond girl was sitting close to the man driving car B. In the back view mirror he saw that car B which just was passed drove into the opposite traffic lane and a frontal collision took place with car $C$ which was running behind him. With the aim to help victims driver 
A turned round and returned to the spot of the road accident. But the view which he saw shocked him: on the driver's seat there was the blond unconscious girl with her bowed bloody head (later it was established, that she had not driver's license). A suspiction aroused who really drove the car and who was the real committer of the accident. Investigators established the car speed, its braking distance and the time for turning round at the maximum possible radius on the road (verges included) and maximum speed in the end of the turning round, also the maximum speed which could be reached (by car A for stop at the spot of collision of cars $B$ and C.

By the use of the formulas presented above the time of car $A$,route" spent for stops, turns around and return to the spot of the collision was evaluated. As it became clear later after the investigation experiment it was established that during this time interval driver $B$ had time to pull and to seat the unconscious girl to the drivercs seat. This fact was certified by the girl's bootees which remained fallen off her legs at the passengercs seat and by the shape of injures on her knees identical to the shape of sharp breakage of the cab panel.

\section{References}

1. Ilarionov, V. A. Examination of road accidents (Автотехническая экспертиза). Moscow: Transport, 1989. 256 p. (in Russian).

2. Borovsky, B. E. Traffic safety of automobile transport (Дорожно-транспортные происшествия (анализ дорожно-транспортных происшествий). Leningrad, 1984. 305 p. (in Russian).

3. Ilarionov, V. А. Examination of road accidents (Исследование дорожно-транспортных происшествий). Moscow: Transport, 1982. 244 p. (in Russian).
4. Lukoševičienè, $O$. The accident analysis and simulation: Monograph. (Autoįvykių analize ir modeliavimas). Vilnius: Technika, 2001. 244 p. (in Lithuanian).

5. Lukoševičienè, O.; Barkauskas, R. Problem of determination of safe distance during overtaking. Transport Engineering (Transportas), No 1 (14). Vilnius: Technika, 1997, p. 67-71 (in Lithuanian).

6. Lukoševičienè, O.; Bogdevičius, M.; Nagurnas, S.; Pečeliūnas, R. Comparative research of a motor car motion in the case of the loss of contact with the road surface. Transport, Vol XIX, No 1. Vilnius: Technika, 2004, p. 20-23.

7. Pečeliūnas, R.; Lukoševičienè, O.; Prentkovskis, O. A mathematical model of the vibrating system equivalent to the vehicle in the mode of emergency braking. Transport, Vol XVIII, No 3. Vilnius: Technika, 2003, p 136142.

8. Momot, W.; Zamecki, W. Selected aspects of active safety in modern road vehicles. Use of integrated antislide mechanisms. In: Proceedings of the 6-th Conference "Problems of reconstruction of road accidents", held in Zakopane on 22-24 October, 1998, p. 313-325 (in Polish).

9. Pankiewicz, B.; Laba, K. Research of parameters having influence on traffic safety for some selected types of road vehicles. In: Proceedings of the 5-th Symposium "Problems of reconstruction of road accidents", held in Zakopane on 24-26 October, 1996, p. 33-51 (in Polish).

10. Han, I.; Park, S.-U. Inverse Analysis of Pre- and PostImpact Dynamics for Vehicle Accident Reconstruction. Vehicle System Dynamics, Vol 36, No 6, 2001, p. 413433.

11. Sharp, R. S. Some Contemporary Problems in Road Vehicle Dynamics. In: Proceedings of the Institution of Mechanical Engineers. Part C. Journal of Mechanical Engineering Science, Vol 214, No 1, 2000, p. 137-148. 